\title{
Diabetes management in Thailand: a literature review of the burden, costs, and outcomes
}

\author{
Chaicharn Deerochanawong $^{1 *}$ and Alessandra Ferrario ${ }^{2}$
}

\begin{abstract}
Management of diabetes represents an enormous challenge for health systems at every level of development. The latter are tested for their ability to continuously deliver high quality care to patients from the day they are diagnosed throughout their life. In this study, we review the status of diabetes management in Thailand and try to identify the key challenges the country needs to address to reduce the current (and future) medical and economic burden caused by the disease.

We conducted a literature review on the burden, costs, and outcomes of diabetes in Thailand. This information was complemented by personal communication with senior officials in the Thai Ministry of Health.

We identified the following priorities for the future management of diabetes in Thailand. First, increasing screening of diabetes in high risk population and promoting annual screening of diabetes complications in all diabetic patients. Second, identifying and addressing factors affecting poor treatment outcomes. Third, policy should specify clear targets and provide and use a monitoring framework to track progress. Fourth, efforts are needed to further improve data availability. Up-to-date data on the medical and economic burden of diabetes representative at the national level and at least the regional level are essential to identify needs and monitor progress towards established targets. Fifth, promotion of a healthy lifestyle for prevention of diabetes through education and quality information delivered to the public.
\end{abstract}

\section{Background}

Thailand is an upper-middle income country in South-East Asia which has achieved impressive economic, social, and health improvements in the past ten years. Between 2007 and 2011 its gross domestic product grew by $7.8 \%$, the percentage of people living below poverty line decreased from $21 \%$ to $8.1 \%$ between 2000 and 2009 , and under-five mortality reached a record low for a country with 13 deaths per 1000 live births in 2010 [1].

The country's disease burden and demographic profile stand out from the South East Asia region's average for its high prevalence of non-communicable diseases (NCDs), higher than the average regional prevalence of HIV/AIDS, and an ageing population [2].

Non-communicable diseases are estimated to account for $71 \%$ of all deaths with cardiovascular diseases representing $27 \%$, cancers $12 \%$, and diabetes $6 \%$ of all deaths [3]. Communicable diseases are estimated to account for $24 \%$ of the

\footnotetext{
* Correspondence: chaicharn_dee@hotmail.com

'Rajavithi hospital, College of Medicine, Rangsit University, Ministry of Public Health, Bangkok 10400 Thailand

Full list of author information is available at the end of the article
}

total years of life lost (regional average 49\%) while noncommunicable diseases account for $55 \%$ (regional average 36\%) [3].

Life expectancy in 2009 was 70 years (66 for males and 74 for females) [4]. The total fertility rate has decreased from 2.4 in 1990 to 1.6 in 2006 [5]. In terms of age structure (based on 2009 figures), 22\% of the Thai population was below age 15 and $11 \%$ above age 60 , the population median age was 33 .

Many factors have contributed to these remarkable health achievements and among these, increased access to health care through universal health insurance is probably one of the key ones. Thailand was the first country in the region able to achieve universal health coverage of its population. Universal health coverage was achieved in 2002 after 27 years of progressive expansion of the universal coverage (UC) scheme to include all the uninsured together with the beneficiaries of the former medical welfare scheme for the poor, the elderly, the disabled and the children, and the voluntary health insurance scheme for the informal sector [6]. This scheme is financed through general taxation and covers $75 \%$ of the Thai population [7].

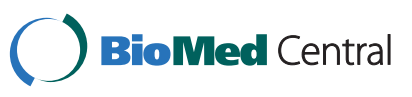

(C) 2013 Deerochanawong and Ferrario; licensee BioMed Central Ltd. This is an Open Access article distributed under the terms of the Creative Commons Attribution License (http://creativecommons.org/licenses/by/2.0), which permits unrestricted use, distribution, and reproduction in any medium, provided the original work is properly cited. 
The two other main public schemes are the civil servants medical benefit scheme, financed through general tax and a non-contributory scheme, and the social security scheme which is financed by equal contributions from employer, employee and the government [8]. In 2010 , these two schemes covered $9 \%$ and $16 \%$ of the population respectively [8].

In terms of the benefit package, the UC scheme covers for in-patient and out-patient care, prescription drugs, laboratory investigations, simple dental care procedures, disease prevention, health promotion, several expensive treatments such as radio- and chemotherapy, surgical procedures, and emergency treatment [7]. Since the end of 2008, renal replacement therapy including renal and peritoneal dialysis and kidney transplantation is also covered by the UC scheme although a co-payment per haemodialysis session is required [9].

Very little information is available on medicines availability in Thailand. According to a survey using the standard WHO/HAI methodology, in 2006 metformin was available in more than $80 \%$ of the surveyed public (20 hospitals) and private (21 private retail pharmacies) health facilities [10]. Diabetes medicine such as metformin, sulfonyurea and insulin are available to all diabetes patients free of charge as part of the UC scheme.

Management of diabetes represents an enormous challenge for health systems at every level of development. The latter are tested for their ability to continuously deliver high quality care to patients from the day they are diagnosed throughout their life. Achieving this requires good coordination across different areas of health care, different levels of care, in addition to trained human resources, an efficient supply system for medicines, a reliable health information system, national and international policies and strategies, and an equitable financing system which ensures access to essential health care services.

In this study, we review the status of diabetes management in Thailand and try to identify the key challenges the country needs to address to reduce the current (and future) medical and economic burden caused by the disease. To do that, we review evidence on the burden of diabetes, including the available data sources, available diagnostic and screening programmes, diabetes treatment, costs and outcomes, and policies implemented.

\section{Methodology}

This study is based on secondary data analysis complemented by primary data collection. A literature review of peer-reviewed and grey literature including policy documents and annual reports of the MoPH and government statistics was undertaken. The following key words were used on the $21^{\text {st }}$ of February 2012 PubMed ((diabetes[Title]) AND Thailand[Title/Abstract]) OR (("Diabetes Mellitus"[Mesh] OR "Diabetes Mellitus, Type
2"[Mesh] OR "Diabetes Mellitus, Type 1"[Mesh]) AND "Thailand"[Mesh]). Studies presenting data on prevalence, incidence, mortality, outcomes (testing, screening rates), and complications were included. We excluded studies which did not present disaggregated data on diabetes (e.g. studies on chronic disease including diabetes). Evidence from the systematic literature review was complemented by primary data obtained through personal communication with Thai diabetes experts and senior public health officials from the Bureau of Non-Communicable Diseases (NCDs) and the Bureau of Policy and Strategy in the Thai Ministry of Public Health (MoPH).

\section{Results}

The search strategy yielded 267 papers, of which 194 were excluded through title and 37 through abstract screening because they did not meet the inclusion criteria. There were 46 final peer-reviewed papers included in the review (Table 1).

\section{Data sources on the burden of diabetes National health examination survey (NHES)}

There is no national longitudinal diabetes registry in Thailand and the main source of prevalence data for diabetes is the national health examination survey (NHES). The aim of the NHES is to estimate the prevalence of particular health conditions and risk factors including obesity, diabetes, and mental, reproductive and elderly health. This survey was completed for the fourth time in 2009 (previous surveys were conducted in 1991, 1997, 2004). In 2009, a national representative sample of 20,450 $(39,290$ in 2009) individuals aged 15 and over was randomly selected using a four-stage sampling strategy from five provinces in each of the four regions and Bangkok. Diabetes prevalence was assessed by fasting blood glucose test and patients identified as diabetic if they had either FPG $>=7.0 \mathrm{mmol} / \mathrm{L}$ but lack of a previous diagnosis (undiagnosed diabetes) or a previous diagnosis of diabetes and intake of glucose lowering drugs during the past two weeks (diagnosed diabetes) [11,12].

Table 1 Literature review results

\begin{tabular}{lll}
\hline $\begin{array}{l}\text { Area of diabetes } \\
\text { management }\end{array}$ & $\begin{array}{l}\text { Number of } \\
\text { references } \\
\text { retrieved }\end{array}$ & References \\
\hline Prevalence and incidence & 17 & {$[11,12,16-25,27-29,33,34]$} \\
Mortality & 2 & {$[35,36]$} \\
Cost of diabetes & 6 & {$[37,38,52,60-62]$} \\
Prevalence of complications & 15 & {$[13,15,49-51,53,60,63-70]$} \\
Cost of complications & 4 & {$[38,52,60,61]$} \\
Outcomes & 6 & {$[50,53,63,67,71,72]$} \\
\hline
\end{tabular}




\section{Diabetes registry project}

In April 2003, 9,419 diabetes patients (both Type 1 and 2) from eleven tertiary care hospitals overall Thailand were enrolled in the Thailand diabetes registry (TDR) project [13]. This project was a collaboration between the Clinical Research Cooperation Network (CRCN) and the Health System Research Institute (HSRI), supported by the Endocrine Society of Thailand. The first objective of this registry was to identify the characteristics of Thai diabetic patients in tertiary care medical centers and to determine the extent of long term diabetic complications. The second objective was to develop and strengthen a clinical research network in Thailand which included experts in diabetes mellitus. The third and final objective was to collect baseline data for future follow-up studies. Crosssectional data were collected from 11 tertiary level hospitals with diabetes clinics between April and December 2003. Demographic data, clinical status of diabetes and its complications were collected to estimate the prevalence of complications and risk factors. Data quality was ensured by regular on-site visits of internal and external auditors. This project also had a second component which was a three-year cohort study from April 2003 to February 2006 to determine the causes of death in diabetes patients.

\section{DiabCare Asia}

DiabCare is an international collaboration between Novo Nordisk Asia Pacific Pte Ltd, Singapore; BioRad Pacific, Hong Kong; and diabetes associations in the participating countries (Bangladesh, China, India, Indonesia, Malaysia, Philippines, Singapore, South Korea, Sri Lanka, Taiwan, Philippines, and Vietnam). The aim of this partnership is to collect evidence on the disease pattern, management, control status, and complications of diabetes in the Asian diabetes population. Patients were recruited in hospitals and followed for 8 to 9 months depending on the study year. DiabCare Asia studies were conducted in 1998 [14], 1991, 2001, 2003, 2008. The next data collection round is planned in late 2012- early 2013. Thailand was surveyed during the 1998, 2001 [15], 2003, and 2008 rounds.

\section{International collaborative study of cardiovascular disease in Asia (InterASIA)}

The InterASIA study on diabetes prevalence, risk factors for cardiovascular diseases, and diabetes management was conducted in 2000 in Thailand and China. This study, founded by Pfizer was a collaboration between universities in Australia, China, Thailand, and the US. The study was based on a nationally representative sample of the Thai general population [16].

\section{Other studies}

Several other studies have been conducted on the burden of diabetes in Thailand. These include investigations on the incidence $[17,18]$ and prevalence of diabetes in population sub-groups [19], prevalence [20,21] and incidence [22-26] of diabetes Type 1 in children, incidence [27] and prevalence [28-30] of gestational diabetes, and prevalence of type 2 diabetes in women with polycystic ovary syndrome [31]. Other studies looked at the prevalence of complications in the Thai diabetes population.

\section{Prevalence and incidence}

\section{Prevalence of diabetes mellitus type 2}

Data from the four NHES indicate that prevalence of diabetes in individuals aged 15 and over has increased over time from $2.3 \%$ in 1991 to $4.6 \%$ in 1997 , to $6.8 \%$ in 2004, and to 6.9\% in 2009 [32] (Figure 1). According to NHES 2009 and 2004, women experienced a higher prevalence than men $[11,12]$. In contrast, findings from the InterASIA study in 2000 did not identify any difference in diabetes prevalence between men and women aged 35 and over (9.3\% men vs. 9.9\% women, $\mathrm{p}=0.6$ ) [16]. At the other end, an earlier study ${ }^{\mathrm{a}}$ among Shinawatra employees, a group of relatively young individuals with high socioeconomic status, found a higher prevalence in men $(2.2 \%$, $\mathrm{N}=1,250)$ than in women $(0.1 \%, \mathrm{~N}=2,365)$ [19].

According to the NHES 2009, prevalence of diabetes was higher in urban areas in comparison to rural areas ( $\mathrm{P}<0.001$ for both sexes) [11]. However, findings from NHES 2004, only found a statistically significant higher prevalence in urban men, in comparison to their rural counterparts, $(\mathrm{P}<0.001)$ but not in urban women $(\mathrm{p}>0.05)$ [12]. The existence of a difference in diabetes prevalence between urban and rural areas in Thailand was confirmed by findings from the InterASIA study in 2000 (12.1\% urban vs. $8.4 \%$ rural, $\mathrm{p}=0.01$, in individuals aged 35 and over) [16]. No difference between urban and rural areas was

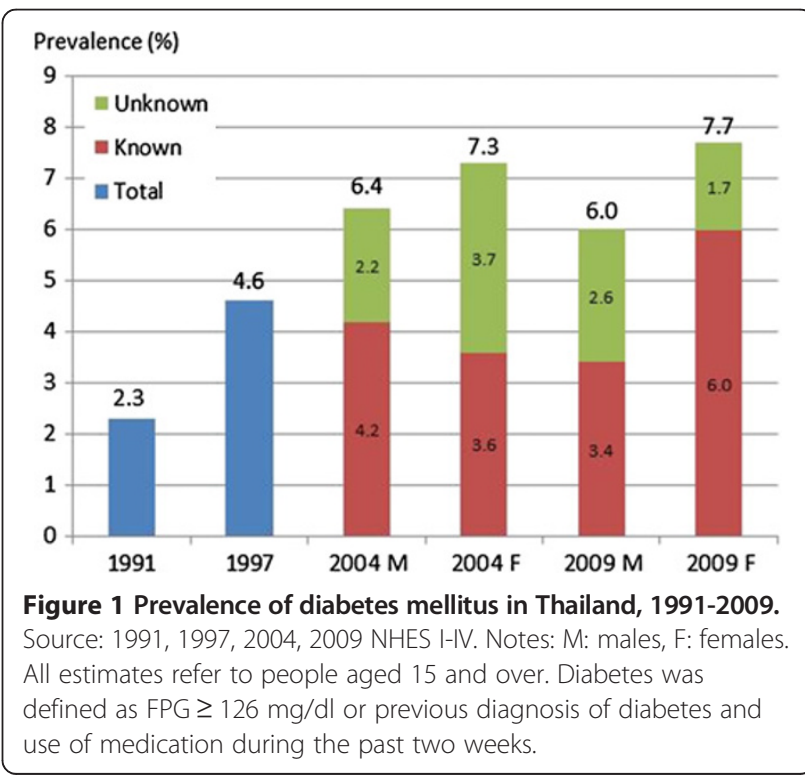


identified in the InterASIA study in 2000 and the NHES survey in 2004 [12,16].

Different studies on diabetes prevalence in Thailand agree that the prevalence of diabetes increases with age and reaches a peak at some point after age 55 depending on the study $[11,12,16,19]$.

An important problem in diabetes care is under-diagnosis as it delays start of treatment and exposes the patient to the risk of complications which leads to higher treatment costs. Levels of under-diagnosis improved between 2004 and 2009 and this improvement was more evident in women than men. Nevertheless, a large proportion of total diabetes patients remains undiagnosed (from $66.5 \%$ to $47.3 \%$ in men and from $51.4 \%$ to $23.4 \%$ in women between 2004 and 2009) [11].

Findings from the NHES 2009 suggest that women have better rates of diagnosis in comparison to men and this difference was statistically significant (there was a difference also in 2004 but this was not statistically significant) $[11,12]$. However, the InterASIA study did not find a statistically significant difference in the proportion of diagnosed patient by gender $(53 \%$ women vs. $47 \%$ men, $\mathrm{p}=0.4$ ) but it found that diagnosis rate was higher for people aged 55 and over $(63 \%>=55$ years old vs. $37 \%<54$ years old, $p=0.01)$ [16].

A comparison of the findings from the NHES in 2009 with results from 2004, shows that the proportion of individuals with diabetes and concomitant hypertension did not significantly decrease in 2009 in both sexes [11]. However, the proportion of women with diabetes who were either abdominally obese or had high total cholesterol $(\geq 5.2 \mathrm{mmol} / \mathrm{L})$ increased from $18 \%$ in 2004 to
23.5\% in 2009 and this difference was significant (both $\mathrm{P}<0.01)$ [11].

An earlier study on the prevalence of DMT2 in children and adolescents (mean age 11.6 years) reported an increase from $5.8 \%$ to $13.3 \%$ between 1986 and 1995 [21]. The authors suggest a link between this increase and the concomitant increase in obesity from $5.8 \%$ to $13.3 \%$ between 1990 and 1996 [21].

\section{Incidence of diabetes mellitus type 1 in children}

Incidence of type 1 diabetes in children in North-East Thailand has increased over the years from in 0.17 per 100,000 in 1984 to 0.3 in 1995 , to 0.39 in 2000 and 1.27 in 2005. In the other regions it has also grown although following a less linear trend particularly in the Central region (Figure 2).

Findings from a study in the Bangkok-Noi district in Bangkok, found an extremely small number of cases (maximum 1 per year) between 1991 and 1995 which, despite the size of the child population in this district, it still resulted in the highest prevalence rates for type 1 diabetes recorded in the country ( 2.18 per 100,000 in 1991,0 in 1992, 1.97 in 1993, 2.06 in 1994, and 2.04 in 1995) [24].

Another study looked at the seasonal variation of diabetes type 1 and found that the peak seasons were the winter and the summer season and lower during the rainy season [20]. This was explained by the higher prevalence of infections in the winter season and the higher levels of pollution in the summer in comparison to the rainy season [20].

All studies (apart from the Bangkok study which did not discuss gender differences) on diabetes type 1 identified

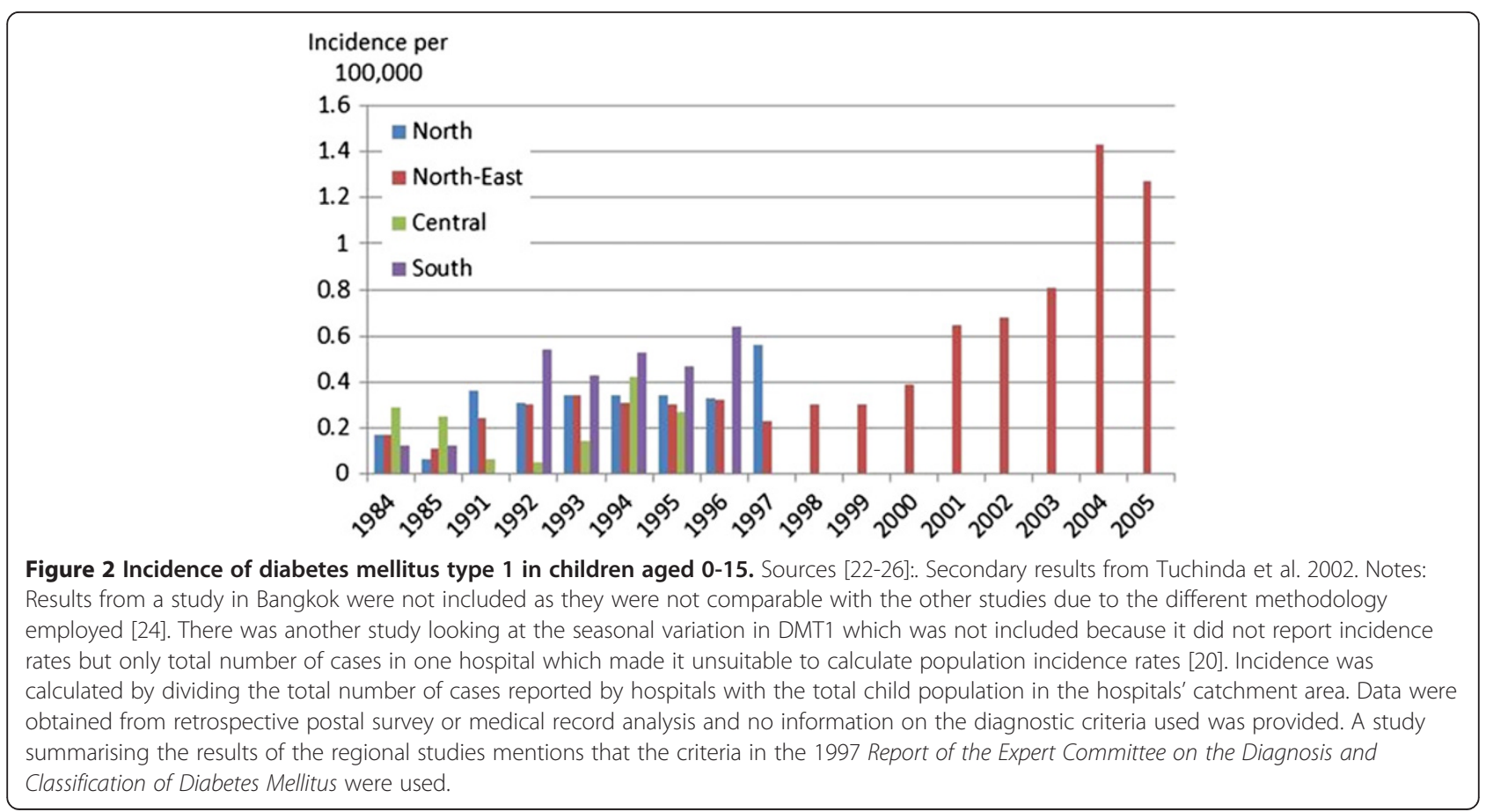


higher incidence in girls, with a girls to boys ratio ranging from 1.3 to 2 . However, none of them tested for statistical significance. Peak age at onset was 10-14 in North and North-East region [22,25,26], 11-15 in the South region [23], and 9-12 in Bangkok [24].

\section{Incidence of diabetes mellitus type $\mathbf{2}$ in adults}

We identified three studies on incidence of DMT2 in adults in urban Thailand from a high socio-economic background [17,18,33]. All the three studies used the diagnostic criteria from the American Diabetes Association (ADA) using fasting plasma glucose tests (FPGs), in addition to that one study also used oral glucose tolerance tests (OGTTs). The most recent study was among professionals and office workers in Bangkok and found an incidence rate in the age-group 35-60, of 17.8 per 1000 person-years (PY) in men and 9.2 per $1000 \mathrm{PY}$ in women in 2005 [17]. A second study among university hospital employees in Bangkok reported an incidence of 13.6 per $1000 \mathrm{PY}$ in men and 6.4 per $1000 \mathrm{PY}$ in women between 2001 and 2005. The study participants were over 35 years old and predominantly female (three-quarters). High BMI $(>25 \mathrm{~kg} / \mathrm{m} 2)$, elevated FPG $(>=96 \mathrm{mg} / \mathrm{dl})$ and alanine aminotransferase levels $(>18 \mathrm{mg} / \mathrm{dl})$ were shown to be independent predictors of DMT2 [18]. Risk of diabetes in men was approximately twice as high as in women but this apparent association was confounded by higher BMI and FPG levels in men and the crude rates showed there was no association between gender and DMT2 [18]. Findings from this study were supported by an earlier study which found an overall incidence of 11.3 per 1000 PY among employees of a state enterprise in Bangkok between 1985 and 1997 [33].

\section{Gestational diabetes}

Four studies on the prevalence of gestational diabetes mellitus (GDM) were identified [27-29,34]. They were hospital based (one hospital per study) and mostly used the diagnostic criteria of the National Diabetes Data Group (NDDG), (50 g + $100 \mathrm{~g}$ OGTT) with one study also comparing NDDG results with WHO criteria (75 g OGTT). All hospitals were located in Bangkok (Figure 3).

The highest prevalence (15.7\%) was estimated in 1995 for women in their $24^{\text {th }}$ to $28^{\text {th }}$ week of gestation using WHO criteria [34]. When using NDDG criteria, the same study estimated a remarkably lower prevalence of $1.4 \%$ [34]. Another study highlighted the importance of the timing of diagnosis, $5.3 \%$ of screened pregnant women were diagnosed with gestational diabetes before their $20^{\text {th }}$ gestational week and an additional $4.9 \%$ of previously undiagnosed women were identified in a second round of testing during their $28^{\text {th }}$ to $32^{\text {nd }}$ week of pregnancy [27]. The 1987-1989 study followed a sub-sample of women after delivery by performing an OGTT using WHO criteria

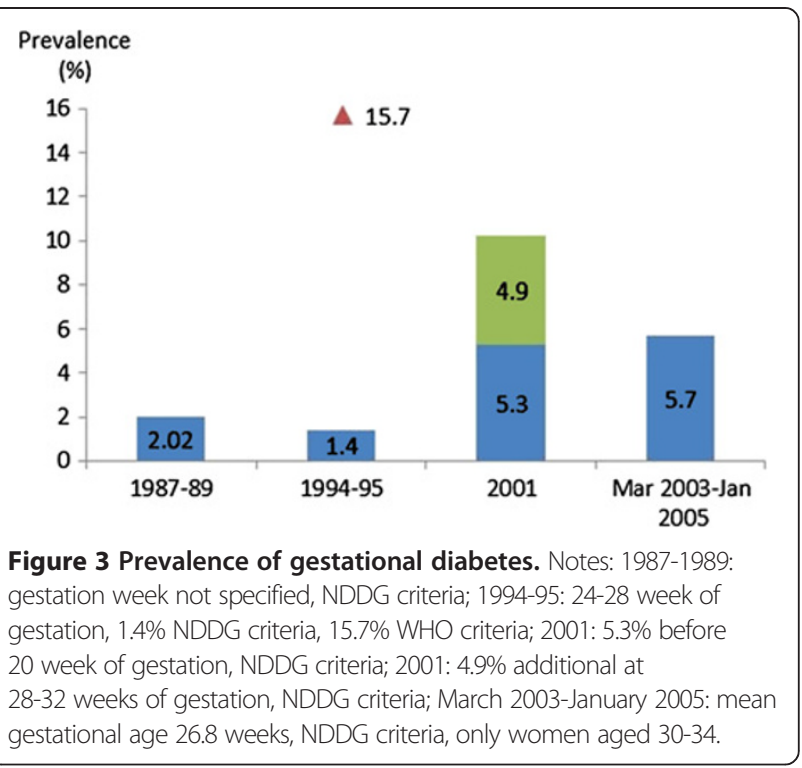

4-6 weeks after childbirth. Results showed that $42.2 \%$ of the 71 women tested had abnormal carbohydrate tolerance, $7 \%$ had diabetes and 35.2\% impaired glucose tolerance (IFG) [28].

The most recent study (March 2003-January 2005) aimed to assess the percentage of pregnancies with GDM which were missed at the time the study was conducted because clinical guidelines in the study hospital limit screening to women at high risk of developing GDM. Eligibility criteria for screening included pregnant women with at least one of the following risk-factors: aged 35 and over, family history of diabetes, previous birth over $4 \mathrm{~kg}$, and other known risk-factors of GDM. This study showed that the prevalence of women aged 30 to 34 was $5.7 \%$, and that of the 32 cases identified, 12 had one risk factor, one had two risk factors (1). More importantly 18 cases of GDM showed no risk factors and would have been missed due to the recommendations in the hospital's guidelines at the time of the study [29].

\section{Mortality}

Results of a comprehensive study to verify causes of death using medical records and verbal autopsy methods, suggest that the leading cause of death in both men and women in 2005 was stroke (9.4\% and $11.3 \%$ respectively) [35]. Diabetes was the second cause of death in women $(8.0 \%)$ and the tenth cause of death in men (3.2\%) in 2005 [35]. This difference is partly explained by the high mortality levels due to road accidents and HIV/AIDS in men. This study also highlighted issues with vital registration where a high percentage of deaths were classified as illdefined. Adjustments to vital registration data led to important changes in the proportion of deaths due to HIV/ AIDS, ischaemic heart disease, and diabetes [35]. The 
proportion of deaths attributable to diabetes reaches its maximum at age 50-79. In 2005, they represented the main cause of death in females (12.3\%) and seventh in males (5.4\%) in this age group [36].

\section{Costs}

Using a micro-costing approach, a study including 475 patients receiving treatment in a hospital in North-East Thailand estimated a median cost of illness per patient of USD 140 (mean USD 881) in 2008 (1 USD = 32 THB, at 2008 prices) [37]. The total annual cost included 23\% direct medical costs, $40 \%$ direct non-medical costs, and $37 \%$ indirect costs [37]. Direct medical costs were driven by inpatient service costs (11\% of total cost of illness), while direct non-medical cost were dominated by the cost of informal care (28\% of total cost of illness). Cost of permanent disability (19\% of total cost of illness) was the most important contributor to informal cost [37]. The median cost of illness increased with age ( $p$-value $<0.001$ ), duration of the disease ( $p$-value $<0.001$ ), the level of fasting blood glucose level ( $\mathrm{p}$-value $=0.002$ ) and number of co-morbidities ( $p$-value $=0.0013$ ) [37]. The median cost of DMT1 was higher than DMT2 (USD 748 vs. USD 140), however this difference was not statistically significant $(\mathrm{p}=0.167$ [37]).

The monthly median cost of informal care based on a sample of 190 informal care givers was estimated at USD\$ 27 using an opportunity cost approach and USD\$ 23 using the proxy good method [38]. Cost of informal care contributed $28 \%$ of total cost of illness of diabetes [37] (Table 2).

Findings from one hospital showed that the cost of informal care accounted for $28 \%$ of the total cost of diabetes [38]. This is likely to have negative repercussions on labour force participation of informal carers who dedicated on average 112 hours per month to informal care and were in their most productive age (25-54 years old) [38].

\section{Diabetes screening and prevention}

Recently, Thailand launched the new "Thailand Healthy Lifestyle Strategy 2011-2020 Plan" endorsed by the Ministry of Public Health [39]. This plan aims to decrease the prevalence, complications, disability, mortality and cost of illness of five major non-communicable diseases including diabetes, hypertension, ischemic heart disease, stroke and cancer. The strategies proposed include: healthy public policy, social mobilization and public communication, community building, surveillance and care system including screening diabetes in high risk population, and capacity building [39].

Yet, to-date, there is still no national screening and no prevention programme in place. There are some examples of successful sub-national diabetes screening and prevention initiatives. These include a prevention model for diabetes in primary care, an educational programme on diabetes prevention for community health care workers, and use of a mobile health unit to screen people living in rural areas for chronic and other health conditions [40-44]. Another example is the development of a simple diabetes risk score to identify Thai patients at high risk of developing diabetes. This score is based on a set of variables (age, BMI, waist circumference, hypertension, and history of diabetes in parents or siblings) which were identified as being significant predictors of diabetes [33]. Measurement of these variables does not require laboratory tests, making the model a cost-effective instrument to identify high risk people to be screened.

However, despite these initiatives have shown initial positive results, they not really been taken beyond the initial pilot phase.

\section{Diabetes treatment}

Thailand has its own guidelines for diabetes treatment (only available in Thai) [45] endorsed by the Thai Diabetes Association, the Endocrine Society of Thailand, and the Ministry of Public Health. The guidelines are updated every three to four years and the latest version was published in 2011. More than 5,000 copies have been published and distributed to primary and secondary care physicians in all the regions of Thailand and they are also available online. However, there is no evidence on how many physicians have adopted these guidelines.

The Thai guidelines resemble the WHO/IDF guidelines $[46,47]$, particularly with reference to screening, prevention, treatment and monitoring. However, use of $\mathrm{HbA1c}$ is not universally recommended for the diagnosis of diabetes because of the lack of standardization of the HbA1c measurement methodology in Thailand and FPG is recommended instead. HbA1c is still generally recommended for monitoring treatment outcomes.

To control diabetes and reduce the risk of developing complications, it is essential to optimise physiological values such as glycaemic levels and blood pressure and to perform regular examinations for nephropathy (albumin excretion, serum creatine), retinopathy (eye), neuropathy (distal symmetric polyneuropathy), and foot disease. Evidence suggests that the frequency with which these tests are performed in Thailand is suboptimal. A study in urban primary care clinics found that annual eye and foot examination was performed only in $21.5 \%$ and $45 \%$ of patients, respectively [15] while the ADA recommends annual testing starting at diagnosis [48].

Another study in the outpatient department of a university hospital found that the annual eye, urine albumin excretion, serum creatinine, and foot examination was performed in $38.4 \%, 42 \%, 83.5 \%$, and $17.3 \%$ of patients in 2006 [49].

The highest rate for DMT2 patients receiving retinal examination, $75.6 \%$ between April to December 2003, was 
Table 2 Direct and indirect cost of diabetes in Thailand

\begin{tabular}{|c|c|c|}
\hline Estimate & Summary of the main features of the study & Reference \\
\hline \multicolumn{3}{|l|}{ Direct and indirect costs } \\
\hline $\begin{array}{l}\text { Median and (mean) cost of illness per type of } \\
\text { patient per year }\end{array}$ & Study year: Oct 2007- Sep 2008 & [60] same study as $[37,38]$ \\
\hline Independent: USD\$ 124 (USD\$ 598), SD 2152 & Reference year for estimate is the fiscal year 2008 & \\
\hline \multirow[t]{2}{*}{ Disabled: USD\$ 811 (USD\$2,700), SD 4982} & $\begin{array}{l}\text { Setting: Waritchaphum Hospital. A 30-bed public } \\
\text { district hospital in Sakhon Nakhon province in } \\
\text { northeastern Thailand }\end{array}$ & \\
\hline & $\begin{array}{l}\text { Sample and study design: } 475 \text { randomly selected } \\
\text { diabetic patients. Prevalence-based cost of illness, } \\
\text { societal perspective }\end{array}$ & \\
\hline Median and (mean) cost of illness per patient & Study year: Oct 2007- Sep 2008 & [37] same study as $[38,60]$ \\
\hline
\end{tabular}

(both disabled and independent) per year:

USD 140 (USD\$ 881),[82.01-552.50]

This included $23 \%$ of direct medical cost, $40 \%$ of direct non-medical cost,

and $37 \%$ of indirect cost

Informal care contributed to $28 \%$

of total cost of illness

Reference year for estimate is the fiscal year 2008

Setting: Waritchaphum Hospital. A 30-bed public district hospital in Sakhon Nakhon province in northeastern Thailand.

Sample and study design: 475 randomly selected diabetic patients. Prevalence-based cost of illness, societal perspective

\section{Direct costs}

Average public treatment cost per patient per year was USD 95

Drug cost was the highest cost component (25\% of total cost), followed by inpatient cost (24\%) and outpatient visit cost (17\%).

Annual average cost of illness (including patients with complications):

\section{USD\$ 158 (THB 6,331)}

Contribution to the total cost: $45 \%$ pharmacy services, $24 \%$ outpatient services, $16 \%$ inpatient services, $11 \%$ laboratory investigations.

Annual cost for DMT2 and DMT1 patients with no complication USD\$ 101 (THB 4,037) and USD\$ 251 (THB 10,059) respectively

\section{Indirect costs}

Median and (mean) cost of informal care per month

Opportunity cost approach: USD 27 (USD\$ 37)

Proxy good method:

USD\$ 23 (USD 34)

Average time spent on informal care was 112 hours per month
Study year: Oct 2007- Sep 2008

[62]

Reference year for estimate is the fiscal year 2008

Setting: Waritchaphum Hospital. A 30-bed public district hospital in Sakhon Nakhon province in northeastern Thailand.

Sample and study design: 475 randomly selected diabetic patients. Retrospective prevalence-based cost of illness study, provider perspective

Study year: October 2000-September 2001

Setting: 30-bed public community hospital in central Thailand

Sample and study design: 186 diabetes patients. Retrospective prevalence-based cost of illness study, provider perspective

Study year: 2008

[38] same study as

Setting: Waritchaphum Hospital. A 30-bed public district hospital in Sakhon Nakhon province in northeastern Thailand.

Sample and study design: 190 informal caregivers. Interview with carers, revealed preference method

SD: Standard deviation, [] interquartile range. 
found in the diabetes registry project which included tertiary diabetes clinics [50].

\section{Diabetes complications and cost of complications}

Overall, prevalence of diabetic retinopathy (DR) ranged between $13.6-31.2 \%$ and it mostly involved non-proliferative DR while the prevalence of diabetes nephropathy ranged between $24-43.8 \%$ and was higher in patients with concomitant DR (Table 3). A variety of vascular complications ranging from absence of foot pulse to ulcer and gangrene leading to foot amputation and stroke were reported.

Two studies reported the prevalence of chronic kidney diseases (CKD). A study in a primary care diabetes centre reported a prevalence of 25-27 (depending on the estimation method) for CKD stage 3-5 in 2007 [51] while a second study in the outpatient department of a tertiary hospital reported a higher prevalence (37\% stage 3, 8.2 stage 4, 2.7 stage 5) in 2006 (Table 3) [49].

Complications have a major impact on the cost of diabetes (Table 3). A study predicted the cost of diabetes to increase up to $232 \%$ depending on the type of complication [52].

The median cost of illness for patients with complications was significantly higher than for people without complications (USD\$ 479.93 vs. USD\$ 115.12, $\mathrm{p}<0.001$ ) and increased with increasing numbers of complications $(\mathrm{p}<0.001)$ [38].

Disability was a major driver of diabetes cost as well as complications due to vascular problems leading to heart failure and corresponding surgery.

In terms of potential savings from better prevention, a study showed that preventing gangrene in DMT2 patients would generate almost USD\$ 250 (THB 10,000) per patient per year [52].

\section{Diabetes outcomes}

There are no national diabetes outcome indicators routinely collected in Thailand. Some diabetes centres report outcomes but this practice is voluntary and not standardised across the country.

The percentage of diabetes patients who were treated and controlled increased between 2004 and 2009 yet it remained low in addition to showing a large gender gap (men $7.7 \%$ in 2004 and $17.5 \%$ in 2009 , women $15.8 \%$ in 2004 and $33.9 \%$ in 2009) [11]. Treatments rates for diagnosed patients were high leaving only $5.6 \%$ men and $1.9 \%$ diagnosed women without treatment [11]. However, 30\% of treated men and $41 \%$ of treated women still did not attain diabetes control [11].

Diabetes control in patients with high blood pressure and high total cholesterol improved in 2009 from 3.4\% to $12.2 \%$ in men and from $6.4 \%$ to $13.8 \%$ in women for hypertension between 2004 and $2009,4 \%$ to $16.3 \%$ in men and $3.8 \%$ to $17.3 \%$ in women for high cholesterol between 2004 and 2009 [11]. However, at the same time the proportion of treated but not controlled patients increased from $25.4 \%$ to $36.3 \%$ in men and from $31.3 \%$ to $54.9 \%$ in women for hypertension and from $7.6 \%$ to $12.6 \%$ in men and from $7.0 \%$ to $18.5 \%$ in women for high cholesterol [11].

Evidence from tertiary care units in earlier studies (2003) shows a very high proportion of diabetes patients with poor glycaemic control (more than $70 \%$ of diabetes patients with HbA1c >7\%) (Table 4). A more recent study (2007) in primary care units shows a slightly better figure (41.3\% of patients with HbA1c levels <7\%) (Table 4) [53].

\section{Access to treatment and inequalities}

In principle, availability of medicines to treat diabetes in Thailand should be adequate since the universal health coverage policy covers more than $75 \%$ of the Thai population (the rest of the population is covered either by the civil servant or the social security scheme). Essential diabetes drugs such as metformin, sulfonylurea, pioglitazone, and insulin are included in the national drug list to which all UC insurees have access to. However, a study on diabetes mortality found that patients on the UC scheme were more likely to die than patients on the civil service scheme (adjusted hazard ratio 1.96, 95\% CI 1.48-2.58, $\mathrm{p}$-value <.005) [54]. Possible reasons for this include lower level of education and socioeconomic status, reduced access to lipid-lowering treatment (at the time of the study) and renal replacement among UC insured people in comparison to civil servants $[54,55]$. When the study was conducted between 2003 and 2006, low-cost generic statins were not yet available. This meant that many patients were not able to access treatment because of the high cost of the original drug. However, since the introduction of generic statins and their inclusion in the UC benefit package, this is no longer an issue.

Inequalities in access to treatment still persist in Thailand despite universal health coverage. Renal replacement therapy (RRT) for example was initially excluded from the benefit package of the UC scheme because the annual cost of haemodyalysis was four times higher (BHT 400,000 , USD 12,100) than the price per quality-adjusted life year threshold set by the National Health Security Office (BHT 100,000, USD 3,0000) [9]. In 2008, thanks to pressure from patients and the public, renal replacement therapy was finally included in the UC benefit package. However, patients opting for haemodyialysis (which is more expensive than peritoneal dialysis) need to pay one third of the treatment cost out-of-pocket which corresponds to an annual cost of (BHT 133,333, USD\$ 4,033) [9] in a country with a per capita gross domestic product of USD\$ 4,608 in 2010 [1]. Further, geographical barriers can affect access to treatment and monitoring for patients living in remote areas. 


\section{Policies}

In 2004, the Ministry of Public Health launched the programme "Healthy Thailand" in an attempt to address the growing burden of NCDs. This programme aimed to promote a healthy lifestyle and to screen $60 \%$ of population aged over 40 years to be screened for IFG and diabetes by the end of 2006 [12]. However, due to lack of data, it is not clear whether this target was achieved.

Reduction of diabetes morbidity and mortality rates due to diabetes is one of the 17 targets included in the Health Thailand Strategy 2004-2015 [56]. However, this target does not include measurable objectives and a strategy to achieve this reduction.

Mobile eye care is the new project that headed by the Ministry of Public Health to improve the access to diabetes care with the aim of preventing blindness from diabetes retinopathy. People living in rural areas often face difficulties in accessing health care. They often have to travel long distances and the transportation costs can be unaffordable to many. One way of alleviating this is the use of mobile clinics which travel to remote areas and provide health care to where people live. The project will be initially implemented in 11 provinces in the northern and north-eastern of Thailand. With time, the plan is to expand the project to cover the entire country [57].

The Thailand healthy lifestyle strategic plan (2011-2020) lists reduction of diabetes incidence, complications, disability, mortality, and expense as one of its five main development goals together with reduction of hypertension, heart disease, cerebrovascular disease and cancer [39]. This should be achieved through the promotion of a balanced diet, adequate physical exercise, and suitable emotional management. However, none of the eighteen short- to long-term performance indicators is linked to measurable objectives in terms of disease burden and cost reduction. Instead they simply mandate for either a reduction or an increase of the relevant indicator. At a higher level, the Thai healthy life-style strategy aims to establish political will, raise public awareness, focus on preventive measures, seek wider collaboration and strengthening active engagement from all stakeholders including public and private sectors, civil society and the general public. Finally, it also seeks to institutionalise organizational structures at all levels of the society, from national to village level, to serve as implementation units responsible for coordination, policy direction, budget allocation, and monitoring and evaluation [39].

\section{Challenges in diabetes management according to Thai diabetes experts and senior public health officials}

The strong features of the national policy and implementation framework for diabetes prevention and control in Thailand include the existence of capable staff and competent healthcare workers throughout Thailand, the presence of academic experts connected nationally and internationally, effective senior level management, strong policy development processes at the national level, and the experience of successfully implementing the tobacco control programme. Weaknesses include unorganised local and mid-level management, staff shortages, high workloads in rural areas, little time or opportunity for continuing training, and weak resource management.

Key opportunities would focus on a strong national policy response to diabetes and other NCDs, a strong network of competent health care workers and hospitals, budget support from both public and private sectors, and scientific and technical support from academics and researchers. The main threats identified are the negative influence of the media leading to changes in lifestyles and increasing risks for diabetes; inconsistent and unreliable information about diabetes disseminated to the public; low public awareness of diabetes issues especially among less well educated people; and high healthcare worker turnover in rural areas.

\section{Discussion}

\section{Prevalence}

The NHES is a nationally representative survey of the health status of the Thai population. NHES III and IV found a higher prevalence of DMT2 in women, older individuals, and in urban areas ${ }^{\mathrm{b}}$. Under-diagnosis was higher in men (2009: 47.3 vs. $23.4 \%$, respectively; $P<0.001)[11,12]$ and in those with less than secondary education [11]. Both surveys showed that nearly all patients who were diagnosed with diabetes were also treated with glucose-lowering medications (2004: men 2.6\%, women 1.7\%; 2009: men 5.6\%, women $1.9 \%$ of diagnosed patients were treated) [11]. However, despite the high treatment rates, the percentage of treated and controlled patients (receiving treatment with glucose-lowering medication and with FPG $<7.2 \mathrm{mmol} / \mathrm{L}$ ) was still low (2004: men 7.7\%, women 15.8\%; 2009: men $17.5 \%$, women $33.9 \%$ treated and controlled patients) [11].

The high percentage of treated patients among diagnosed diabetics suggests the availability of a resilient health care system in terms of access to treatment. However, access is hampered by the low diagnosis rates which need to be improved by increased screening of high-risk groups. A risk score to identify individuals at high-risk of developing diabetes was developed for the Thai population [33]. Wider implementation of this lowcost instrument can help identify high-risk individuals to be screened and therefore to increase the percentage of diabetes patients who is diagnosed. This would allow earlier start of treatment and could help in preventing part of the costs of complications arising from neglect of the disease. Another issue is the low rates of treated and controlled patients. To address these issues evidence is needed on factors responsible for poor treatment 
Table 3 Prevalence of diabetes complications in Thailand

Prevalence of diabetic retinopathy (DR)

$15.1 \%$ DR, 11.6\% non-proliferative, 3.5\% proliferative DR

$31.2 \%(n=86), 25 \%(n=69)$ non proliferative and $6.2 \%(n=17)$ proliferative DR

$31.4 \%(n=2105), 22 \%(n=1475)$ non-proliferative and $9.4 \%(n=630)$ proliferative DR

DMT2 and DMT1

30.7\% ( $n=2187), 21.3 \%$ ( $n-1516)$ non-proliferative, 9.4\% $(n=671)$ proliferative

DMT1

$21.6 \%(n=75), 10.9 \%(n=38)$ non-proliferative and $10.7 \%(n=27)$ proliferative DR

22\% ( $n=667), 19 \%(n=576)$ non-proliferative DR, 3\% $(n=91)$ proliferative DR

$13.6 \% \mathrm{DR}$

Comprehensive eye examination:

$19.2 \%$ non-proliferative, $1.1 \%$ proliferative for the right eye, $18.5 \%$ non-proliferative, $1.3 \%$ proliferative for the left eye

Photography:

23.8\% NDR, 1.4\% PDR for the right eye,

$22.6 \%$ NDR, 1.3\% PDR for the left eye

\section{Diabetic nephropathy (DN)}

DN without DR

Study year: January 2007-September 2008

Study year: March-October 2007

Setting: 13 primary care units in urban areas

Sample and study design: Cross-sectional study, ADA criteria

287 diabetic patients (79 males, 208 females)

Study year: 1 Jan-31 Dec 2006

Setting:1 tertiary hospital, out-patient department

Sample and study design: 722 diabetes patients. Retrospective records review of DMT2 patients

Study year: April-December 2003

Setting: 11 tertiary diabetes centres

Sample and study design: 6,707 diabetes Type

2 patients (4,434 females, 2,273 males). Cross-sectional,

hospital based study. Thailand diabetes registry project

Study year: April-December 2003

Setting: 11 tertiary care medical centres

Sample and study design: 9,419 diabetes patients, 65.9\% females, 94.6\% DMT2, 4.5\% DMT1, 0.1\% MODY.

Cross-sectional, hospital based study. Thailand diabetes registry project

Study year: April-December 2003

Setting: 11 tertiary diabetes centres

Sample and study design: 347 diabetes Type

1 patients (215 females, 132 males). Cross-sectional study of diabetes patients in 11 hospitals. Thailand diabetes registry project.

Study year: January-December 2002

Setting: All community hospital in Lampang province

Sample and study design: 3,049 diabetes patients (838 males, 2,211 females). Cross-sectional study in hospitals

Study year: 2001

Setting: 8 provincial hospitals plus $4-5$ district hospitals providing primary health care services in each province. Total number of sites: 37

Sample and study design: 1,078 diabetes patients (300 males, 778 females). Cross-sectional study

Study year: NA

Setting: Trang provincial hospital

Sample and study design: 714 diabetes patients.

Cross-sectional, hospital based study

62.8\% normo-albuminuria, 26\% micro-albuminuria,

$11.2 \%$ macro-albuminuria 
Table 3 Prevalence of diabetes complications in Thailand (Continued)

\begin{tabular}{ll}
\hline & Setting: 7 public hospitals: Bangkok (3), \\
& Nakhonpathom (1), Prathumthani (1), \\
& Prathumthani (1), and Prathumthani (1) \\
& Sample and study design: 877 patients \\
DN and DR & with diabetes Type 2 (ADA criteria), \\
& collection of urine samples. Cross-sectional \\
& study in the out-patient department of \\
& seven public hospitals
\end{tabular}

$18.5 \%$ normo-albuminuria, $35.5 \%$

micro-albuminuria, 48\% macro-albuminuria

Microalbuminuria 28.7\%, macroalbuminuria 5.7\%, $85 \%$ of them were non-DR and $15 \%$ DN and DR including $8 \%$ with both DN and DR
Prevalence of DN was 42.9\%: 19.7\% microalbuminuria, 23.2\% overt nephropathy.

Prevalence of DN 17\%
Study year: March-October 2007

Setting: 13 primary care units in urban areas

Sample and study design: 287 diabetes patients, 79 males, 208 females.

Cross-sectional study, ADA criteria

Study year: April-December 2003

Setting: 11 tertiary diabetes centres

Sample and study design: Children and adolescents diabetes, 58 Type 1 and 22 Type 2, were screened for nephropathy. Cross-sectional study. Thailand diabetes registry project

Study year: April-December 2003

Setting: 11 tertiary centres

Sample and study design: 4,875 diabetes patients, $63.8 \%$ females. Cross-sectional study, hospital based study. Thailand diabetes registry project

Study year: 2001

Setting: 8 provincial hospitals plus $4-5$ district

hospitals providing primary health care

services in each province. Total number of sites: 37

Sample and study design: 1,078 diabetes patients (300 males, 778 females).

Cross-sectional study

\section{Vascular complications}

Previous history of any lower extremity amputation: $0.9 \%$ right foot lesion, $0.6 \%$ left foot lesion

Study year: Aug 2005-March 2007

Diminished or absent pedal pulses $7.4 \%$ right foot lesion, $7.7 \%$ left foot lesion

Low-risk ulcerative foot 3.7\%

Setting: Diabetic clinic in a university hospital in Northern Thailand

Sample and study design: 438 diabetic patients. Baseline data of patients attending the clinic were collected

High-risk ulcerative foot $0.2 \%$

1.2\% acute foot ulcer/gangrene, $6.9 \%$ healed foot ulcer

Study year: 2001

Setting: 8 provincial hospitals plus 4-5 district hospitals providing primary health care

services in each province. Total

number of sites: 37

Sample and study design: 1,078 diabetes patients (300 males, 778 females).

Cross-sectional study

Study year: 1 Jan-31 Dec 2006

Sample and study design: 722 diabetes patients, Retrospective review of medicinal records of DMT2 patients 
Table 3 Prevalence of diabetes complications in Thailand (Continued)

\author{
DM duration more than 15 years vs. \\ DM duration \\ less than 15 years group \\ DN $49.4 \%$ vs. $33.9 \%$, DR $54.3 \%$ vs. $22.8 \%$; \\ myocardial \\ infarction $9.4 \%$ vs. $3.5 \%$, peripheral \\ arterial disease, \\ $17.3 \%$ vs. $5.5 \%$, foot ulcer $13.4 \%$ vs. $5.3 \%$, stroke \\ $9.4 \%$ vs. $7.0 \%$ and amputation $5.5 \%$ vs. $2.0 \%$; all \\ $\mathrm{p}$ values less than 0.01 )
}

Study year: April-December 2003

Setting: 11 tertiary diabetes centres

\begin{abstract}
Sample and study design: 9,284 adult diabetes
Type 2 patients registered to the Diabetes

registry project, 2,244 patients with duration

of diabetes more than 15 years and 7,040

patients with duration of diabetes less than

15 years. The longer duration group was on

average older than the shoter duration group.

Cross-sectional study. Thailand

diabetes registry project

Study year: April-December 2003

Setting: 11 tertiary care medical centres

Sample and study design: 9,419 diabetic

patients, 65.9\% females, 94.6\% DMT2, 4.5\%

DMT1, 0.1\% MODY. Cross-sectional, hospital

based study. Thailand diabetes registry project
\end{abstract}

Study year: April- August 2007

Setting: Six primary health care units in Udon

Thani province

using Cockcroft-Gault formula and

Modification of Diet in Renal Disease

(MDRD) formula respectively

Sample and study design: 714 diabetic patients,

542 females and 174 males. Cross-sectional

study, cluster random sampling method

Study year: 1 Jan-31 Dec 2006

[49]

Setting: 1 tertiary hospital, out-patient department

Sample and study design: 722 diabetes patients.

Retrospective review of medical records of

DMT2 patients

7.7\% patients had renal insufficiency and

Study year: April-December 2003

Setting: 11 tertiary centres

Sample and study design: 4,875 patients,

$63.8 \%$ females. Cross-sectional study, hospital

based study. outcomes (e.g. patient compliance to treatment, performance of monitoring and self-management, etc.)

\section{Incidence of type 1 in children}

Data on diabetes type 1 in Thai children aged 0-15 suggests an increased incidence over the last 20 years from less than 0.3 cases per 100,000 in 1984 in all regions to 1.27 cases per 100,000 in the North-East region in 2005. However, interpretation of this data requires caution. Apart from the Bangkok study, all the other studies restricted their data collection to hospitals. Incidence was calculated by dividing the total number of cases reported by hospitals with the total child population in the hospitals' catchment area. Although hospitals' response rate was generally high (range: $84.7 \%$ to $94.5 \%$ ) $[22,25]$, this means that in addition to not capturing diabetes type 1 cases who did not attend a hospital, the results were also importantly influenced by missing data from hospitals that did not participate in the survey.

Under-diagnosis is likely to have played a major role in the 1990s and first half of the 2000s because of incomplete insurance coverage which created barriers to health care access. Furthermore, apart from the NorthEast region, no data is available after 1997 and the most recent incidence data for the North-East region are for 2005 . 
Table 4 Control of diabetes and of HbA1c levels

\begin{tabular}{|c|c|c|}
\hline Estimate & $\begin{array}{l}\text { Summary of the main } \\
\text { features of the study }\end{array}$ & Reference \\
\hline HbA1c levels $<7 \%$ & Study year: March-October 2007 & {$[53]$} \\
\hline \multirow[t]{2}{*}{$41.3 \%$} & $\begin{array}{l}\text { Setting: } 13 \text { primary care units } \\
\text { in urban areas }\end{array}$ & \\
\hline & $\begin{array}{l}\text { Sample and study design: } \\
287 \text { diabetic patients, } 79 \text { males, } \\
208 \text { females. Cross-sectional study, } \\
\text { ADA criteria }\end{array}$ & \\
\hline HbA1c levels $<7 \%$ & Study year: July 2007 & {$[72]$} \\
\hline \multirow[t]{2}{*}{$29.7 \%$} & $\begin{array}{l}\text { Setting: diabetes clinic in a } \\
\text { community hospital }\end{array}$ & \\
\hline & $\begin{array}{l}\text { Sample and study design: } \\
325 \text { diabetic patients (who had } \\
\text { diabetes for at least one year), } \\
114 \text { males, } 221 \text { females. } \\
\text { Cross-sectional study. }\end{array}$ & \\
\hline \multirow{3}{*}{$\begin{array}{l}30.2 \% \text { of the } \\
\text { participants achieved } \\
\text { HbA1c levels of } \\
\text { less than } 7 \%\end{array}$} & Study year: April-December 2003 & {$[71]$} \\
\hline & Setting: 11 tertiary diabetes centres & \\
\hline & $\begin{array}{l}\text { Sample and study design: 8,913 } \\
\text { Type } 2 \text { diabetes patients aged } 18 \\
\text { and older ( } 3,012 \text { males and 5,901 } \\
\text { females). Cross-sectional study. } \\
\text { Thailand diabetes registry project }\end{array}$ & \\
\hline HbA1c levels $<7 \%$ & Study year: April-December 2003 & [67] \\
\hline DMT1: $17 \%$ & Setting: 11 tertiary diabetes centres & \\
\hline DMT2: 21.6\% & $\begin{array}{l}\text { Sample and study design: Children } \\
\text { and adolescents diabetes, } 58 \text { Type } 1 \\
\text { and } 22 \text { Type 2, Cross-sectional study. } \\
\text { Thailand diabetes registry project }\end{array}$ & \\
\hline \multicolumn{3}{|l|}{ HbA1c levels 7-8\% } \\
\hline \multicolumn{3}{|l|}{ DMT1: 20\% } \\
\hline \multicolumn{3}{|l|}{ DMT2: 15.2\% } \\
\hline \multicolumn{3}{|l|}{ HbA1c levels 8-9\% } \\
\hline \multicolumn{3}{|l|}{ DMT1: 15\% } \\
\hline \multicolumn{3}{|l|}{ DMT2: 15.2\% } \\
\hline \multicolumn{3}{|l|}{ HbA1c levels >9\% } \\
\hline \multicolumn{3}{|l|}{ DMT1: $47.6 \%$} \\
\hline DMT2: 48.2\% & & \\
\hline
\end{tabular}

Notes: standard deviation (SD).

\section{Incidence of type 2 diabetes in adults}

The latest data on the incidence of DMT2 in Thai adults show an incidence rate of 13.6 in men per $1000 \mathrm{PY}$ and 6.4 per $1000 \mathrm{PY}$ in women [18]. However this data is out-of-date as it refers to the time period 2001 to 2005 and is not representative of the entire country as it based on urban high-socio-economic status individuals working in the healthcare sector.

\section{Gestational diabetes}

Due to different gestational weeks and age of the prospective mother when the glucose test was conducted, it is not possible to draw definitive conclusions on the evolution of the prevalence of GDM over time. Data only included women attending antenatal care which might be biased towards higher socio-economic groups due to the lack of universal coverage at the time of the surveys. Despite these challenges, two main findings seem to emerge. First, a very large difference (eleven-fold) was reported when using different diagnostic criteria (NDDG (1.4\%) vs. WHO criteria (15.7\%)) on the same sample of women and another recent study that used the new criteria of international association of the diabetes and pregnancy study groups (IADPSG) found the prevalence of GDM in Bangkok was 23.0\% [58]. Second, use of eligibility criteria which limit screening to women at high risk of developing GDM independently of their age have shown to miss more than $50 \%$ of cases among women aged 30 and over.

\section{Costs}

Data on the cost of diabetes without complications mainly comes from a study in one-hospital in North-East Thailand. Generalisability of local studies on cost of illness is affected by variation of input prices across the country, the level of care of the hospital analysed, and the patient status. One study in Thailand for example showed that a visit to the regional hospital was 3.48 times more expensive than a visit to a community hospital (THB 1,181 vs. THB 339 in 2002) [59]. Another issue was the uncertainty and large variation around the results (very large standard deviations were reported).

\section{Complications and cost of complications}

According to data from the Thailand diabetes registry, diabetic nephropathy was the most common complication accounting for $43.9 \%$ of all complications followed by retinopathy $(30.7 \%)$, ischaemic heart disease $(8.1 \%)$, and cerebrovascular disease (4.4\%) [13]. Another study in the out-patient department of a university hospital found a lower prevalence for diabetic nephropathy, 37\%, a similar prevalence for retinopathy, $31.2 \%$ but a substantially higher prevalence for cardiovascular and cerebrovascular disease, $28.9 \%$ and $10.6 \%$, respectively.

The first study also highlighted the existence of high prevalence of risk factors for diabetes and its complications (dyslipidaemia, hypertension, and obesity (BMI $\geq$ $25 \mathrm{~kg} / \mathrm{m}^{2}$ ) was $73.3 \%, 63.3 \%$, and $52.6 \%$ respectively) [13].

Complications are the single largest driver of the cost of diabetes because they require more intensive care such as hospitalisation and often surgery. Studies showed that the median cost of illness for patients with complications in comparison to patients without complications was USD\$ 480 vs. USD 115 [37], USD\$ 190 for diabetic foot, USD\$ 260 for cerebrovascular event, USD\$ 336 for gangrene in comparison to USD\$ 101 for patients without complications [52]. Interestingly, the latter study which was based on retrospective data analysis and cost forecast, 
Table 5 Cost of diabetes complications in Thailand

\begin{tabular}{|c|}
\hline Cost of complications \\
\hline $\begin{array}{l}\text { Median cost per year (USD\$ at } 2008 \\
\text { prices) of diabetes for patients: }\end{array}$ \\
\hline $\begin{array}{l}\text { With complications: USD\$ } 480 \\
(n=148, S D=3,023)\end{array}$ \\
\hline $\begin{array}{l}\text { Without complications: USD\$ } 115 \\
(\mathrm{n}=327, \mathrm{SD}=2,648)\end{array}$ \\
\hline $\begin{array}{l}\text { Independent: USD\$ } 124 \\
(n=411, S D=2,152)\end{array}$ \\
\hline $\begin{array}{l}\text { Any level of disability: USD\$ } 811 \\
(n=61, S D=4,982)\end{array}$ \\
\hline $\begin{array}{l}\text { Mildly disabled: USD\$ } 668 \\
(n=51, S D=3,848)\end{array}$ \\
\hline $\begin{array}{l}\text { Moderate disability: USD\$2,374 } \\
(\mathrm{n}=7, \mathrm{SD}=7,940)\end{array}$ \\
\hline $\begin{array}{l}\text { Severely disabled: USD\$ } 4,891 \\
(n=1, S D=0)\end{array}$ \\
\hline $\begin{array}{l}\text { Very severely disabled: USD\$4,378 } \\
(n=5, S D=7,622)\end{array}$ \\
\hline
\end{tabular}

Average spending per hospital admission as percentage of GDP per capita and in USD (constant 2000):

Total: 62\% (USD\$ 1682)

without complications: 49\% (USD\$ 1,329)

with myocardial infarction: 108\% (USD\$ 2,930)

with congestive heart failure: 93\% (USD\$ 2523)

with peripheral vascular disease: 116\% (USD\$ 3147)

with ulcer: 106\% (USD\$ 2,876)

with hemiplegia: 63\% (USD\$1,709)

with moderate/severe renal disease: 90\% (USD\$ 2,442)

Median cost of illness per year:

With complications USD\$ 480

( $n=148, I Q R=129-1552$ )

Without complications USD\$ 115

( $n=327, I Q R=74-286)$

With microvascular complications

USD\$ $641(n=59, I Q R=207-2,268)$

With macrovascular complications

USD\$ $367(n=11, I Q R=111-2,463)$

With micro- and macrovascular complications USD\$ 666

( $\mathrm{n}=11, \mathrm{IQR}=201-2,707)$

With microvascular complications

and cataract USD\$ $745(n=23, I Q R=376-1,358)$

Cataract USD\$151 ( $\mathrm{n}=44, \mathrm{IQR}=94-587)$
Summary of the main features of the study

Study year: 2007-2008

References

[60]

Setting: Waritchaphum hospital in Sakhon Nakhon province (North-East Thailand)

Sample and study design: 475 randomly selected diabetic patients

Study year: 2006-2008

Setting: University hospital in Bangkok

Sample and study design: The study included all 8,596 (94\% insured, 6\% uninsured) DM patients admitted in the hospital during 2006-2008. Retrospective data analysis.

Study year: 2007-2008

[37] same study as [60]
[61] USD equivalents of the percentage of GDP spent per hospital admission were calculated by the authors using GDP data (USD constant 2000, 2,712 in 2007) from The World Bank.
Setting: Waritchaphum hospital in Sakhon Nakhon province (North-East Thailand)

Sample and study design: 475

randomly selected diabetic patients. Micro-costing approach. 
Table 5 Cost of diabetes complications in Thailand (Continued)

\begin{tabular}{|c|c|c|}
\hline Predicted cost per year of DM T2 $(\mathrm{N}=186)$ : & Study year: 2001 & {$[52]$} \\
\hline $\begin{array}{l}\text { without complications USD\$ } 101 \\
\text { (BHT 4,037) }\end{array}$ & $\begin{array}{l}\text { Setting: } 30 \text {-bed public hospital } \\
\text { in central Thailand }\end{array}$ & \\
\hline $\begin{array}{l}\text { with hypertension USD\$ } 117 \\
\text { (BHT 4,686) }\end{array}$ & $\begin{array}{l}\text { Sample and study design: } 186 \text { diabetic } \\
\text { patients. Retrospective prevalence-based } \\
\text { cost of illness study. Multiple regression } \\
\text { analysis was used to predict cost of DM } \\
\text { for various types of complications. }\end{array}$ & \\
\hline \multicolumn{3}{|l|}{$\begin{array}{l}\text { with hyperlipidaemia USD\$ } 144 \\
\text { (BHT 5,775) }\end{array}$} \\
\hline \multicolumn{3}{|l|}{$\begin{array}{l}\text { with diabetic foot USD\$190 } \\
\text { (BHT 7,603) }\end{array}$} \\
\hline \multicolumn{3}{|l|}{$\begin{array}{l}\text { with hyperglycaemia USD\$209 } \\
\text { (BHT 8,369) }\end{array}$} \\
\hline \multicolumn{3}{|l|}{$\begin{array}{l}\text { with hypoglycaemia USD\$247 } \\
\text { (BHT 9,860) }\end{array}$} \\
\hline \multicolumn{3}{|l|}{$\begin{array}{l}\text { with cerebrovascular accident USD\$ } \\
260 \text { (BHT 10,418) }\end{array}$} \\
\hline \multicolumn{3}{|l|}{ with gangrene USD\$336 (BHT 13,417) } \\
\hline (40 THB $=1$ USD\$ at 2011 prices) & & \\
\hline
\end{tabular}

Notes: SD: standard deviation, IQR: inter-quartile range.

found that the highest proportion of treatment cost was caused by pharmacy services (45\%) followed by outpatient (24\%) and inpatient services (16\%) [52]. The first study found a similar share of inpatient costs (11\%) but in addition to direct costs it also estimated indirect costs and the contribution of informal care, mortality, and permanent disability to the cost of illness $(27.8 \%, 17.5 \%, 18.7 \%$, respectively) [37] (Table 5). This data shed some light on substantial indirect costs caused by morbidity and reduced ability to work. Preventing complications, and related disability, by improving diabetes control is therefore of paramount importance to reduce the health and economic burden of diabetes.

There is a large variation in the estimates of the prevalence and costs of complications in Thailand. More studies at different levels of care and covering all the regions are needed to get a full picture of the prevalence and the cost of diabetes complications in the country.

\section{Conclusions}

Based on the results of this study, the following priorities for the future management of diabetes in Thailand were identified. First, increasing screening of diabetes in high risk population and promoting annual screening of diabetes complications in all diabetic patients. Second, identifying and addressing factors affecting poor treatment outcomes in light of reducing the number of treated but not controlled patients and therefore reducing their likelihood of developing complications. Third, policy should specify clear targets and provide and use a monitoring framework to track progress.
Fourth, efforts are needed to further improve data availability. Up-to-date data on the medical and economic burden of diabetes representative at the national level and at least the regional level are essential to identify needs and monitor progress towards established targets. Priority areas for data collection include incidence of diabetes in children and adults, prevalence of GDM, cost of diabetes and its complications, and treatment compliance and outcomes at individual level. Availability of prevalence data is good due to the regular NHES, however, these surveys are only conducted every 5-7 years.

Fifth, promotion of a healthy lifestyle for prevention of diabetes through education and quality information delivered to the public.

Efforts to address these issues have already started in some areas of the country but not overall. In order to achieve this, a multisectoral effort including concerted policy actions from a variety of policy makers (beyond the ministry of public health and including other relevant ministries) and of public opinion leaders as well as interventions involving public and private delivery channels is required.

\section{Endnotes}

${ }^{a}$ Study year is not specified but the publication data is 2000 so it is very likely to refer to the late 1990 s.

${ }^{\mathrm{b}}$ In 2004 prevalence in urban areas was higher for men but not for women.

\section{Abbreviations}

BHT: Thai Bath; BMI: Body mass index; T2/1: Type 2/1; DALYs: Disability adjusted life years; DM: Diabetes mellitus; DT: Diabetes retinopathy; DN: Diabetes nephropathy; FPG: Fasting plasma glucose; GDM: Gestational 
diabetes mellitus; HbA1c: Glycaeted haemoglobin; MoPH: Ministry of Public Health; NCDs: Non-communicable diseases; NHES: National Health Examination Survey; NDDG: National Diabetes Data Group; OGTT: Oral glucose tolerance test; RRT: Renal replacement therapy; TDR: Thailand diabetes registry; UC: Universal coverage; USD: United States dollar.

\section{Competing interests}

This study was funded by NovoNordisk Switzerland. The funder had no involvement with the study design, data analysis, and paper writing. Both the authors declare no conflict of interest.

\section{Authors' contributions}

Both authors' contributed to data acquisition, analysis and paper writing. CD conducted interviews with the MoPH, CD and AF conducted the systematic literature review, CD wrote the first draft, CD and AF redrafted and critically revised the paper and approved the final manuscript.

\section{Acknowledgments}

This paper is part of a research project based at the London School of Economics and Political Science (LSE) on Diabetes International which is funded with an unrestricted educational grant by Novonordisk. The authors gratefully acknowledge Ms Marsha Fu for her excellent editorial assistance.

\section{Author details}

'Rajavithi hospital, College of Medicine, Rangsit University, Ministry of Public Health, Bangkok 10400 Thailand. ${ }^{2}$ LSE Health, London School of Economics and Political Science, Houghton Street, WC2A 2AE London, UK.

Received: 19 November 2012 Accepted: 4 March 2013

Published: 14 March 2013

\section{References}

1. Data. [http://data.worldbank.org]. Accessed 01.03.2012.

2. Bundhamcharoen $K$, Odton P, Phulkerd S, Tangcharoensathien V: Burden of disease in Thailand: changes in health gap between 1999 and 2004. BMC Public Health 2011, 11(53). doi:10.1186/1471-2458-11-53.

3. World Health Organization: Non-communicable diseases country profile. Geneva, Switzerland: WHO; 2010.

4. World Health Organization: Global Health Observatory. Geneva, Switzerland: WHO; 2010.

5. World Health Organization: Country cooperation strategy at a glance Thailand: 2010.

6. Tangcharoensathien $V$, Swasdiworn $W$, Jongudomusk $P$, Srithamrongswat $S$, Patcharanarumol W, Prakongsai $\mathrm{P}$, Thammathataree J: Universal coverage scheme in Thailand: Equity outcomes and future agendas to meet challenges. In Health systems financing The path to universal coverage World Health Report. Bangkok, Thailand; 2010.

7. Tangcharoensathien V, Patcharanarumol W, Vasavid C, Prakongsai P, Jongudomusk P, Srithamrongswat S, Thammathataree J: Thailand Health Financing Review 2010. Bangkok, Thailand: Thai working group on Observatory of Health Systems and Policy; 2010.

8. Prakongsai $P$, Limwattananon S, Tangcharoensathien V: The Equity impact of the universal coverage policy: lessons from Thailand. In Innovations in health system finance in developing and transitional economies, Volume 21. Edited by Hanson K, Chernichovsky D. London: Emerald Group Publishing Limited; 2009:57-81.

9. Treerutkuarkul A: Thailand: health care for all, at a price. Bull World Health Organ 2010, 88(2):84-85.

10. Sooksriwong C, Yoongthong W, Riewpaiboon A, Pongcharoensuk P Thavorncharoensab M, Chaikledkaew U, Suwattanapreeda S: Medicine Pricing, Availability and Affordability in Thailand. In Report of a survey conducted in Bangkok (Capital City), Phitsanulok (North), Suratthani (South), and Nakornrachaseema (Northeast). Bangkok, Thailand: The Office of Food and Drug Administration and The Ministry of Public Health; 2007.

11. Aekplakorn W, Chariyalertsak S, Kessomboon P, Sangthong R, Inthawong R, Putwatana P, Taneepanichskul S, Thai National Health Examination Survey IV Study Group: Prevalence and management of diabetes and metabolic risk factors in Thai adults the Thai national health examination survey IV, 2009. Diabetes Care 2011, 34(9):1980-1985.

12. Aekplakorn W, Abbott-Klafter J, Premgamone A, Dhanamun B, Chaikittiporn C, Chongsuvivatwong V, Suwanprapisa T, Chaipornsupaisan W, Tiptaradol S,
Lim SS: Prevalence and management of diabetes and associated risk factors by regions of Thailand: Third National Health Examination Survey 2004. Diabetes Care 2007, 30(8):2007-2012

13. Rawdaree $P$, Ngarmukos C, Deerochanawong C, Suwanwalaikorn S, Chetthakul T, Krittiyawong S, Benjasuratwong Y, Bunnag P, Kosachunhanun $\mathrm{N}$, Plengvidhya N, et al: Thailand diabetes registry (TDR) project: Clinical status and long term vascular complications in diabetic patients. J Med Assoc Thai 2006, 89(Suppl.1):S1-S9.

14. Chuang L, Tsai S, Huang B, Tai T, on behalf of the Diabcare-Asia Study Group: The status of diabetes control in Asia - a cross-sectional survey of 24317 patients with diabetes mellitus in 1998. Diabet Med 2002, 19(12):978-985.

15. Nitiyanant W, Chetthakul T, Sang-A-Kad P, Therakiatkumjorn C, Kunsuikmengrai K, Yeo JP: A survey study on diabetes management and complication status in primary care setting in Thailand. J Med Assoc Tha 2007, 90(1):65-71.

16. Aekplakorn W, Stolk R, Neal B, Suriyawongpaisal P, Chongsuvivatwong V Cheepudomwit S, Woodward M, InterASIA Collaborative Group: The Prevalence and Management of Diabetes in Thai Adults. The International Collaborative Study of Cardiovascular Disease in Asia. Diabetes Care 2003, 25(10):2758-2763.

17. Jiamjarasrangsi W, Aekplakorn W: Incidence and predictors of type 2 diabetes among professional and office workers in Bangkok, Thailand. J Med Assoc Thai 2005, 88(12):1896-1904.

18. Jiamjarasrangsi W, Lohsoonthorn V, Lertmaharit S, Sangwatanaroj S: Incidence and predictors of abnormal fasting plasma glucose among the university hospital employees in Thailand. Diabetes Res Clin Pract 2008, 79(2):343-349.

19. Bhuripanyo K, Ruangratanaamporn O, Mahanonda N, Leowattana W, Sriratanasathaavorn C, Chotinaiwattarakul C, Kangkagate C, Chaithiraphan S: Impaired fasting glucose, diabetes mellitus and coronary risk factors. J Med Assoc Thai 2000, 83(Suppl.2):S146-S152.

20. Likitmaskul S, Angsusingha K, Morris S, Kiattisakthavee P, Chaichanwatanakul K, Tuchinda C: Type 1 diabetes in Thai children aged 0-14 years. J Med Assoc Thai 1999, 82(8):826-832.

21. Likitmaskul S, Kiattisathavee P, Chaichanwatanakul K, Punnakanta L, Angsusingha $K$, Tuchinda C: Increasing prevalence of type 2 diabetes mellitus in Thai children and adolescents associated with increasing prevalence of obesity. J Pediatr Endocrinol Metab 2003, 16(1):71-77.

22. Panamonta O, Laopaiboon M, Tuchinda C: Incidence of childhood type 1 (insulin dependent) diabetes mellitus in northeastern Thailand. J Med Assoc Thai 2000, 83(8):821-824.

23. Patarakijvanich N, Tuchinda C: Incidence of diabetes mellitus type 1 in children of southern Thailand. J Med Assoc Thai 2001, 84(8):1071-1074.

24. Tuchinda C, Likitmaskul S, Unachak K, Panamonta O, Patarakijavanich N, Chetthakul T: The epidemiology of type 1 diabetes in Thai children. J Med Assoc Thai 2002, 85(6):648-652.

25. Unachak K, Tuchinda C: Incidence of type 1 diabetes in children under 15 years in northern Thailand, from 1991 to 1997. J Med Assoc Thai 2001 84(7):923-928

26. Panamonta O, Thamjaroen J, Panamonta M, Panamonta N, Suesirisawat C: The rising incidence of type 1 diabetes in the northeastern part of Thailand. J Med Assoc Thai 2011, 94(12):1447-1450.

27. Boriboonhirunsarn D, Sunsaneevithayakul $P$, Nuchangrid M: Incidence of gestational diabetes mellitus diagnosed before 20 weeks of gestation. J Med Assoc Thai 2004, 87(9):1017-1021.

28. Serirat $S$, Deerochanawong $C$, Sunthornthepvarakul T, Jinayon $P$ : Gestational diabetes mellitus. J Med Assoc Thai 1992, 75(6):315-319.

29. Sumeksri P, Wongyai S, Aimpun P: Prevalence of gestational diabetes mellitus (GDM) in pregnant women aged 30 to 34 years old at Phramongkutklao Hospital. J Med Assoc Thai 2006, 89(Suppl 4):S94-S99.

30. Chanprapaph P, Sutjarit C: Prevalence of gestational diabetes mellitus (GDM) in women screened by glucose challenge test (GCT) at Maharaj Nakorn Chiang Mai Hospital. J Med Assoc Thai 2004, 87(10):1141-1146.

31. Weerakiet S, Srisombut C, Bunnag P, Sangtong S, Chuangsoongnoen N, Rojanasakul A: Prevalence of type 2 diabetes mellitus and impaired glucose tolerance in Asian women with polycystic ovary syndrome. Int J Gynaecol Obstet 2001, 75(2):177-184.

32. Ministry of Public Health: Thailand Health Profile Report 2008-2010. Edited by Wibulpolprasert S. Bangkok, Thailand: The War Veterans Organizations of Thailand; 2011. 
33. Aekplakorn W, Bunnag P, Woodward M, Sritara P, Cheepudomwit S, Yamwong S, Yipintsoi T, Rajatanavin R: A risk score for predicting incident diabetes in the Thai population. Diabetes Care 2006, 29(8):1872-1877.

34. Deerochanawong C, Putiyanun C, Wongsuryrat $M$, Serirat $S$, Jinayon P: Comparison of National Diabetes Data Group and World Health Organization criteria for detecting gestational diabetes mellitus. Diabetologia 1996, 39(1070-1073):1070-1073.

35. Rao C, Porapakkham Y, Pattaraarchachai J, Polpraser W, Swampunyalert N, Lopez A: Verifying causes of death in Thailand: rationale and methods for empirical investigation. Population Health Metrics 2010, 8(11):148-154

36. Porapakkham Y, Rao C, Pattaraarchachai J, Polprasert W, Vos T, Adair T, Lopez A: Estimated causes of death in Thailand, 2005: implications for health policy. Population Health Metrics 2010, 8(14):191-198.

37. Chatterjee S, Riewpaiboon A, Piyauthakit P, Riewpaiboon W, Boupaijit K, Panpuwong N, Archavanuntagul V: Cost of diabetes and its complications in Thailand: a complete picture of economic burden. Health Soc Care Community 2011, 19(3):289-298.

38. Chatterjee S, Riewpaiboon A, Piyauthakit P, Riewpaiboon W: Cost of informal care for diabetic patients in Thailand. Prim Care Diabetes 2011, 5(2):109-115.

39. Ministry of Public Health: Thailand healthy lifestyle strategic plan 2011-2020. Bangkok, Thailand: The War Veterans Organizations of Thailand; 2011:58.

40. Sranacharoenpong K, Hanning R: Diabetes prevention education program for community health care workers in Thailand. J Community Health 2012, 37(3):610-618.

41. Swaddiwudhipong W, Lerdlukanayonge $P$, Chaovakiratipong C, Nguntra P, Mahasakpan P, Koonchote S, Boonmak C: Screening assessment of the elderly in rural Thailand by a mobile unit. Trans R Soc Trop Med Hyg 1996, 90(3):223-227

42. Swaddiwudhipong W, Mahasakpan P, Chaovakiratipong C, Nguntra P, Tatip Y, Koonchote S, Boonmak C, Tharmaphornpilas P: Screening assessment of persons 40-59 years of age in rural Thailand by a mobile health unit. J Med Assoc Thai 1999, 82(2):131-139.

43. Sranacharoenpong K, Hanning R: Developing a diabetes prevention education programme for community health-care workers in Thailand: formative findings. Prim Health Care Res Dev 2011, 12(4):357-369.

44. Oba N, McCaffrey R, Choonhapran P, Chutug P, Rueangram S: Development of a community participation program for diabetes mellitus prevention in a primary care unit, Thailand. Nurs Health Sci 2011, 13(3):352-359.

45. Thai Diabetes Treatment Guideline 2011. http://www.diabassocthai.org/ index.php?option $=$ com_content $\&$ view $=$ article $\& i d=12 \% 3 \mathrm{~A}-2551-\&$ catid $=2 \%$ 3A2011-01-25-09-11-02\&ltemid=6\&lang=th. Accessed 08.04.2013.

46. WHO, IDF: Definition and diagnosis of diabetes mellitus and intermediate hyperglycaemia: Report of a WHO/IDF consultation. Geneva, Switzerland: World Health Organization/International Diabetes Federation; 2006:54.

47. WHO, IDF: Screening for type 2 diabetes: Report of a WHO and IDF meeting. Geneva, Switzerland: World Health Organization/International Diabetes Federation; 2003:54.

48. American Diabetes Association: Executive Summary: Standards of Medical Care in Diabetes 2012. Diabetes Care 2012, 35(1). doi:10.2337/dc12-s004.

49. Sriwijitkamol A, Moungngern Y, Vannaseang S: Assessment and prevalences of diabetic complications in 722 Thai type 2 diabetes patients. J Med Assoc Thai 2011, 94(Suppl 1):S168-S174.

50. Chetthakul T, Deerochanawong C, Suwanwalaikorn S, Kosachunhanun N, Ngarmukos C, Rawdaree P, Krittiyawong S, Leelawatana R, Bunnag P, Plengvidhya $\mathrm{N}$, et al: Thailand diabetes registry project: prevalence of diabetic retinopathy and associated factors in type 2 diabetes mellitus. J Med Assoc Thai 2006, 89(Suppl 1):S27-S36.

51. Narenpitak S, Narenpitak A: Prevalence of chronic kidney disease in type 2 diabetes in primary health care unit of Udon Thani province, Thailand. J Med Assoc Thai 2008, 91(10):1505-1513.

52. Riewpaiboon A, Pornlertwadee P, Pongsawat K: Diabetes cost model of a hospital in Thailand. Value Health 2007, 10(4):223-230.

53. Mayurasakorn K, Somthip N, Caengow S, Chulkarat N, Wanichsuwan M: Glycemic control and microvascular complications among type 2 diabetes at primary care units. J Med Assoc Thai 2009, 92(8):1094-1101.

54. Pratipanawatr $T$, Rawdaree $P$, Chetthakul T, Bunnag $P$, Ngarmukos $C$, Benjasuratwong Y, Leelawatana R, Kosachunhanun N, Plengvidhya N, Deerochanawong C, et al: Thailand Diabetic Registry cohort: predicting death in Thai diabetic patients and causes of death. J Med Assoc Thai 2010, 93(Suppl 3):S12-S20.

55. Pratipanawatr $T$, Rawdaree $P$, Chetthakul T, Bunnag P, Ngarmukos $C$, Benjasuratwong $Y$, Leelawatana R, Kosachunhanun N, Plengvidhya N, Deerochanawong $C$, et al: Thailand diabetes registry project: current status of dyslipidemia in Thai diabetic patients. J Med Assoc Thai 2006, 89 (Suppl 1):S60-S65.

56. Ministry of Public Health: Thailand health profile 2005-2007. Bangkok, Thailand: The War Veterans Organizations of Thailand; 2008.

57. Mobile Eye Care WDF 08-395. http://www.worlddiabetesfoundation.org/ projects/thailand-wdf08-395. Accessed 08.04.2013.

58. Sacks DA, Hadden DR, Maresh M, Deerochanawong C, Dyer AR, Metzger BE, Lowe LP, Coustan DR, Hod M, Oats JJN, et al: Frequency of gestational diabetes mellitus at collaborating centers based on IADPSG consensus panel-Recommended criteria. Diabetes Care 2012, 3:526-528.

59. Upakdee N, Pannarunothai S: Medical charges for outpatients: a case study in three provinces using health insurance data. J Health Sci 2003, 12:775-787

60. Riewpaiboon A, Chatterjee S, Riewpaiboon W, Piyauthakit P: Disability and cost for diabetic patients at a public district hospital in Thailand. Int J Pharm Pract 2011, 19(2):84-93.

61. Goldhaber-Fiebert JD, Li H, Ratanawijitrasin S, Vidyasagar S, Wang XY, Aljunid S, Shah N, Wang Z, Hirunrassamee S, Bairy KL, et al: Inpatient treatment of diabetic patients in Asia: evidence from India, China, Thailand and Malaysia. Diabet Med 2010, 27(1):101-108.

62. Riewpaiboon A, Chatterjee S, Piyauthakit P: Cost analysis for efficient management: diabetes treatment at a public district hospital in Thailand. Int J Pharm Pract 2011, 19(5):342-349.

63. Chetthakul T, Likitmaskul S, Plengvidhya N, Suwanwalaikorn S, Kosachunhanun N, Deerochanawong C, Krittiyawong S, Leelawatana R, Benjasuratwong $Y$, Bunnag $P$, et al: Thailand diabetes registry project: prevalence of diabetic retinopathy and associated factors in type 1 diabetes mellitus. J Med Assoc Thai 2006, 89(Suppl 1):S17-S26.

64. Eppens MC, Craig ME, Jones TW, Silink M, Ong S, Ping YJ: Type 2 diabetes in youth from the Western Pacific region: glycaemic control, diabetes care and complications. Curr Med Res Opin 2006 22(5):1013-1020

65. Jenchitr W, Samaiporn S, Lertmeemongkolchai $P$, Chongwiriyanurak T, Anujaree P, Chayaboon D, Pohikamjorn A: Prevalence of diabetic retinopathy in relation to duration of diabetes mellitus in community hospitals of Lampang. J Med Assoc Thai 2004, 87(11):1321-1326.

66. Leelawattana R, Pratipanawatr T, Bunnag P, Kosachunhanun N, Suwanwalaikorn S, Krittiyawong S, Chetthakul T, Plengvidhya N, Benjasuratwong $Y$, Deerochanawong $C$, et al: Thailand diabetes registry project: prevalence of vascular complications in long-standing type 2 diabetes. J Med Assoc Thai 2006, 89(Suppl 1):S54-S59.

67. Likitmaskul S, Wacharasindhu S, Rawdaree P, Ngarmukos C, Deerochanawong C, Suwanwalaikorn S, Chetthakul T, Bunnag P, Kosachunhanun N, Plengvidhaya N, et al: Thailand diabetes registry project: type of diabetes, glycemic control and prevalence of microvascular complications in children and adolescents with diabetes. J Med Assoc Thai 2006, 89(Suppl 1):S10-S16.

68. Krairittichai U, Potisat S, Jongsareejit A, Sattaputh C: Prevalence and risk factors of diabetic nephropathy among Thai patients with type 2 diabetes mellitus. J Med Assoc Thai 2011, 94(Suppl 2):S1-S5.

69. Supapluksakul S, Ruamviboonsuk P, Chaowakul W: The prevalence of diabetic retinopathy in Trang province determined by retinal photography and comprehensive eye examination. J Med Assoc Tha 2008, 91(5):716-722.

70. Krittiyawong S, Ngarmukos C, Benjasuratwong Y, Rawdaree P, Leelawatana R, Kosachunhanun N, Plengvidhya N, Deerochanawong C, Suwanwalaikorn $S$, Pratipanawatr $T$, et al: Thailand diabetes registry project: prevalence and risk factors associated with lower extremity amputation in Thai diabetics. J Med Assoc Thai 2006, 89(Suppl 1):S43-S48.

71. Kosachunhanun N, Benjasuratwong Y, Mongkolsomlit S, Rawdaree $P$, Plengvidhya N, Leelawatana R, Bunnag P, Pratipanawatr T, Krittiyawong S, Suwanwalaikorn $S$, et al: Thailand diabetes registry project: glycemic control in Thai type 2 diabetes and its relation to hypoglycemic agent usage. J Med Assoc Thai 2006, 89(Suppl 1):S66-S71.

72. Worawongprapa O: Glycemic control in diabetes with metabolic syndrome in community hospital. J Med Assoc Thai 2008, 91(5):641-647. 
73. Ngarmukos C, Bunnag P, Kosachunhanun N, Krittiyawong S, Leelawatana R, Prathipanawatr T, Plengvidhya N, Benjasuratwong Y, Suwanwalaikorn S, Deerochanawong C, et al: Thailand diabetes registry project: prevalence, characteristics and treatment of patients with diabetic nephropathy. J Med Assoc Thai 2006, 89(Suppl 1):S37-S42.

74. Kosachunhanun N, Tongprasert S, Rerkasem K: Diabetic foot problems in tertiary care diabetic clinic in Thailand. Int I Low Extrem Wounds 2012, 11(2):124-127.

doi:10.1186/1744-8603-9-11

Cite this article as: Deerochanawong and Ferrario: Diabetes

management in Thailand: a literature review of the burden, costs, and outcomes. Globalization and Health 2013 9:11.

\section{Submit your next manuscript to BioMed Central and take full advantage of:}

- Convenient online submission

- Thorough peer review

- No space constraints or color figure charges

- Immediate publication on acceptance

- Inclusion in PubMed, CAS, Scopus and Google Scholar

- Research which is freely available for redistribution 